\title{
Selenized milk casein in the diet of BALB/c nude mice reduces growth of intramammary MCF-7 tumors
}

Jenny M Warrington ${ }^{1}$, Julie JM Kim', Priska Stahel ${ }^{1}$, Scott RL Cieslar ${ }^{1}$, Roger A Moorehead ${ }^{2}$, Brenda L Coomber ${ }^{2}$, Milena Corredig ${ }^{3}$ and John P Cant ${ }^{*}$

\begin{abstract}
Background: Dietary selenium has the potential to reduce growth of mammary tumors. Increasing the Se content of cows' milk proteins is a potentially effective means to increase Se intake in humans. We investigate the effects of selenized milk protein on human mammary tumor progression in immunodeficient BALB/c nude mice.

Methods: Four isonitrogenous diets with selenium levels of $0.16,0.51,0.85$ and $1.15 \mathrm{ppm}$ were formulated by mixing low- and high-selenium milk casein isolates with a rodent premix. MCF-7 cells were inoculated into the mammary fat pad of female BALB/c nude mice implanted with slow-release 17 -estradiol pellets. Mice with palpable tumors were randomly assigned to one of the four diets for 10 weeks, during which time weekly tumor caliper measurements were conducted. Individual growth curves were fit with the Gompertz equation. Apoptotic cells and Bcl-2, Bax, and Cyclin D1 protein levels in tumors were determined.

Results: There was a linear decrease in mean tumor volume at 70 days with increasing Se intake $(P<0.05)$, where final tumor volume decreased 35\% between 0.16 and $1.15 \mathrm{ppm}$ Se. There was a linear decrease in mean predicted tumor volume at 56, 63 and 70 days, and the number of tumors with a final volume above $500 \mathrm{~mm}^{3}$, with increasing Se intake $(P<0.05)$. This tumor volume effect was associated with a decrease in the proportion of tumors with a maximum growth rate above $0.03 \mathrm{day}^{-1}$. The predicted maximum volume of tumors $\left(V_{\max }\right)$ and the number of tumors with a large $V_{\text {max }}$, were not affected by Se-casein. Final tumor mass, Bcl-2, Bax, and Cyclin D1 protein levels in tumors were not significantly affected by Se-casein. There was a significantly higher number of apoptotic cells in high-Se tumors as compared to low-Se tumors.

Conclusions: Taken together, these results suggest that turnover of cells in the tumor, but not its nutrient supply, were affected by dairy Se. We have shown that $1.1 \mathrm{ppm}$ dietary Se from selenized casein can effectively reduce tumor progression in an MCF-7 xenograft breast cancer model. These results show promise for selenized milk protein as an effective supplement during chemotherapy.
\end{abstract}

Keywords: Selenium, Casein, Mammary tumor, MCF-7 cells

\footnotetext{
* Correspondence: jcant@uoguelph.ca

${ }^{1}$ Centre for Nutrition Modelling, Department of Animal and Poultry Science, University of Guelph, Guelph, ON N1G 2W1, Canada

Full list of author information is available at the end of the article
} 


\section{Background}

Selenium is an essential trace mineral that is required at greater than $0.15 \mathrm{ppm}$ in the diet of humans and laboratory animals to maximize synthesis of selenoproteins [1]. Se becomes toxic at levels greater than $400 \mathrm{ug} / \mathrm{d}$ in the diet and deficient at levels lower than $40 \mathrm{ug} / \mathrm{d}$. Supranutritional supplementation of seleniumat 1 to 4 ppm has shown great promise in cancer prevention $[2,3]$, though the mechanism of the effect remains elusive. Transformed cells are often able to persist and replicate due to a disruption in the regulatory circuitry controlling programmed cell death. Both organic and inorganic forms of Se have been observed to induce apoptosis in several cancer cell lines in vitro, including human prostate cancer cells, human leukemia cells, and murine mammary epithelial cells [4-8].

Due to the global variation in soil Se content, there exist Se-deficient populations in the world [9] Further, those populations that receive adequate levels of Se in their diet are likely still below the level of Se required to prevent cancer [10]. Increasing the selenium content of cow's milk has been suggested to be an effective way of improving selenium intake in humans. The supplementation of Se-yeast in a cow's diet is the most effective method for increasing milk Se content, where Se is incorporated into milk proteins as selenomethionine during milk synthesis [11]. Consumption of $1 \mathrm{ppm}$ Se from selenized milk protein increased apoptosis and decreased proliferation of chemically induced colon tumors, and decreased the number of mice with tumors 30 weeks after carcinogen exposure [12]. Effects of dairy Se on mammary tumor development has not previously been investigated although organic forms of Se providing 2 ppm dietary Se decreased by $50 \%$ the number of chemically induced mammary tumors 22 weeks after carcinogen exposure in rats [6].

The objective of this study was to investigate the effects of selenized milk protein on human mammary tumor progression in immunodeficient BALB/c nude mice. The effects of selenized milk protein on apoptotic circuitry in these human epithelial MCF-7 breast tumor cells were also investigated. We found that each increment in Se intake between 0.16 and 1.15 ppm of diet dry matter caused a decrease in tumor volume after 8 weeks on diets.

\section{Methods}

\section{Cell culture}

Estrogen receptor-positive MCF-7 breast cancer cells were cultured in Eagle's Minimum Essential Medium (ATCC Catalog No. 30-2003) supplemented with $0.01 \mathrm{mg} / \mathrm{mL}$ human insulin and $10 \%$ fetal bovine serum. Cells were incubated at $37^{\circ} \mathrm{C}$ and $5 \% \mathrm{CO}_{2}$ in air atmosphere. Passage was conducted when cells reached confluency every two to three days. Cells were collected for injection at $80 \%$ confluency by centrifuging at $125 \mathrm{xg}$ for 5 minutes. Cells

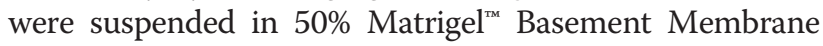
Matrix (BD Biosciences, Mississauga, ON), 50\% media at a final concentration of $3 \times 10^{6}$ cells $/ 100 \mathrm{uL}$.

\section{Casein isolation and diet formulation}

To generate low- and high-Se caseins, Holstein dairy cows were fed 0 or $4.5 \mathrm{ppm}$ (dry basis) selenium as Seyeast (Sel-Plex, Alltech Inc., Kentucky, USA) on top of a basal diet of $0.15 \mathrm{ppm}$ Se from $\mathrm{Na}_{2} \mathrm{SeO}_{3}$. Diets were fed for 3 weeks, after which milk was collected and stored at $4^{\circ} \mathrm{C}$ until pasteurized and skimmed at $70^{\circ} \mathrm{C}$ with a flow rate of $1.5 \mathrm{~L} / \mathrm{min}$. The skim milk was cooled to $45^{\circ} \mathrm{C}$ and an acid casein precipitate was formed by adding lactic acid ( $88 \%$ food grade) to a $\mathrm{pH}$ of 4.6 . The casein precipitate was washed twice with cold deionized water, collected on cheese cloth, and drained overnight. The casein was separated into trays and freeze dried at $-20^{\circ} \mathrm{C}$ for 3 days. The product was then ground and stored at $4^{\circ} \mathrm{C}$.

Final Se concentrations in the low- and high-Se caseins, measured by fluorometry (AOAC, 2005) were 0.87 and $9.3 \mathrm{ppm}$, respectively. These low- and high-Se caseins were then sent to Research Diets Incorporated to be mixed with a standard rodent to produce four diets with varying Se levels. AIN-76 diets (Research Diets Inc., New Brunswick, NJ) containing 0.16, 0.51, 0.85, and 1.15 ppm Se (dry basis) were produced by mixing low- and high-Se caseins, to a final concentration of $20 \%$ casein in each diet (Table 1). After mixing, diets were gamma-

Table 1 Composition of experimental diets

\begin{tabular}{lc}
\hline Ingredient & (g/100 g diet) \\
\hline Casein & 20.0 \\
L-Cystine & 0.28 \\
Corn starch & 29.9 \\
Maltodextrin & 3.3 \\
Sucrose & 32.1 \\
Cellulose & 4.7 \\
Soybean oil & 2.4 \\
Lard & 1.9 \\
Mineral mix, no added Se & 0.95 \\
Calcium phosphate dibasic & 1.23 \\
Calcium carbonate & 0.52 \\
Potassium citrate $\mathrm{H}_{2} \mathrm{O}$ & 1.56 \\
Vitamin mix & 0.95 \\
Choline bitartrate & 0.19 \\
\hline
\end{tabular}


irradiated and stored at $4^{\circ} \mathrm{C}$. Proximate nutrient composition of diets was determined at a commercial laboratory according to AOAC (2005) methods.

\section{Animal trials}

All mice were housed and cared for according to guidelines established by the Animal Care Committeeat the University of Guelph and the Canadian Council on Animal Care. Seventy-two female, athymic, BALB/c nude mice, 6-8 weeks old, were purchased from Charles River Laboratories (Senneville, QC). Mice were housed in autoclaved, ventilated cages and provided with autoclaved water. Water and food were offered ad libitum. Food consumption was not measured, however body weights were measured biweekly throughout the trial. They were exposed to a 12-hour light/12-hour dark cycle and fed standard mouse chow (Research Diets, New Brunswick, NJ) once daily at $1800 \mathrm{~h}$. After 1 week of acclimatization, mice were xenotransplanted under isoflurane anaeasthesia with $3 \times 10^{6}$ MCF-7 cells in the mammary fat pad and 90 -day release $17 \beta$-estradiol pellets $(0.5 \mathrm{mg} /$ pellet; Innovative Research of America, Sarasota, FL) subcutaneously between scapulae.

Beginning one week post-surgery, tumor volumes were assessed daily using caliper measurements. Tumor volumes $(V)$ were calculated as $\mathrm{V}=1 \times \mathrm{w}^{2} / 2$, where $\mathrm{l}$ is length and $w$ is width of the tumor. Once tumor volume reached approximately $60 \mathrm{~mm}^{3}$ mice were randomized to one of the four treatment diets. Only mice with tumors that reached a palpable volume within 3 weeks after implantation were included in the trial. The animal trial involved 72 mice; 18 mice per diet. 7, 8, 4, and 5 mice from treatments $1,2,3$, and 4 , respectively, were euthanized during this trial. These mice were prematurely euthanized for exhibiting criteria for euthanasia; either clinical signs or because tumor size exceeded $10 \%$ of body weight. Each cage of 5 mice was furnished with 2 plastic feeders that were replaced at $1200 \mathrm{~h}$ daily with 10 g powdered diet.

After 10 weeks on experimental diets, mice were sacrificed by $\mathrm{CO}_{2}$ asphyxiation, and tumors and livers were excised, weighed and frozen in liquid nitrogen prior to storage at $-80^{\circ} \mathrm{C}$. A section of tumor was also stored in $10 \%$ formalin solution for at least 24 hours, after which it was embedded in paraffin wax.

\section{Western blotting}

Western blots were performed on tumor tissue from each subject to measure levels of cyclin D1, Bcl-2, and Bax. Tumor tissues were homogenized in $2 \mu \mathrm{L}$ RIPA lysis buffer/mg tissue, containing $10 \mu \mathrm{L} / \mathrm{mL}$ protease inhibitor. Protein concentrations in tissue homogenates were measured according to Bradford (1976) with bovine serum albumin as the standard. Membranes were blocked for one hour with $5 \%$ (wt/vol) skim milk at $4{ }^{\circ} \mathrm{C}$ and incubated with rabbit anti-cyclin D1 (1:1000 dilution, Cell Signaling, Danvers, MA), rabbit anti-Bcl-2 (1:1000 dilution, Cell Signaling, Danvers, MA), rabbit anti-Bax (1:1000 dilution, Cell Signaling, Danvers, MA) or rabbit anti- $\beta$-tubulin (1:1000 dilution, Cell Signaling, Danvers, MA) on a rocking platform. After washing with TBST (TBS, 1\% (vol/vol) Tween 20), membranes were incubated with peroxidase-conjugated anti-rabbit secondary antibody (1:2000 dilution, Cell Signaling, Danvers, MA) for 1 hour at room temperature on a rocking platform. Immunoreactive proteins were visualized by chemiluminescence (ECL Western Blotting Detection Reagents) using horseradish peroxidase-linked secondary antibody (anti-rabbit immunoglobulin, 1:2000 dilution). $\beta$-tubulin was used to normalize protein loads between blots.

\section{Detection of apoptosis}

Wax-embedded tissues from the 4 largest tumors on each treatment were sectioned at $5 \mu \mathrm{m}$ onto polarized slides for colorimetric TUNEL assay. To visualize and quantify tumor cell death, TUNEL assay was performed using an in situ Cell Death Detection Kit (Promega, Madison, WI, USA) according to the manufacturer's protocol. Nuclei were counterstained using Harris-modified hematoxylin, and slides were mounted. The number of apoptotic cells was expressed as a percentage of total cells, counting 1500-2000 nuclei per sample.

\section{Se Status}

Tumor samples were freeze-dried and digested in nitric acid in a $90^{\circ} \mathrm{C}$ sand bath. The digestate was then brought up to volume $(10 \mathrm{~mL})$ and analyzed using Inductively Coupled Plasma Mass Spectroscopy (AOAC, 2005). Selenium values are reported on a dry matter basis.

\section{Modeling}

To compare tumor growth characteristics across treatments, trajectories of individual tumor volume $\left(V_{t}\right)$ versus time $(\mathrm{t})$ were fitted with the Gompertz equation,

$$
\mathrm{V}_{\mathrm{t}}=\mathrm{V}_{\max } \mathrm{e}^{-\mathrm{be}}
$$

where $\mathrm{V}_{\text {max }}$ is the asymptotic upper bound that the tumor volume approaches as time approaches infinity, and b and $\mathrm{c}$ describe the growth. The maximum specific growth rate (c) occurs at the inflection point, $t_{\text {inflection }}=\ln (\mathrm{b}) / \mathrm{c}$. Best estimates for parameters $V_{\max }, b$ and $c$ were obtained by minimizing residual sums of squares between predicted and observed tumor volumes using Excel Solver. The parameter estimates were then used to generate predicted volumes at weekly intervals after assignment to diet. Goodness of fit to each curve was assessed by root mean 
square prediction error (rMSPE), as a percentage of the mean observed tumor volume, calculated as:

$$
\text { rMSPE } \%=\sqrt{\frac{\sum_{i=1}^{n}\left(\text { pred }_{i}-\text { obs }_{i}\right)^{2}}{n}} / \sum_{\frac{i=1}{n} o b s_{i}}^{n}
$$

where pred $_{\mathrm{i}}$ is the $\mathrm{i}$-th prediction, $\mathrm{obs}_{\mathrm{i}}$ is the $\mathrm{i}$-th observation, and $\mathrm{n}$ is the number of observations.
Specific growth rate (a) at any point in time can be calculated using the following:

$$
\mathrm{a}=\mathrm{bce} \mathrm{e}^{-\mathrm{ct}}
$$

The specific growth rate at $70 \mathrm{~d}$ of dietary treatment was calculated as:

$$
\mathrm{a}_{\text {final }}=\mathrm{bce}^{-\mathrm{c} 70}
$$

\section{Statistical analysis}

The general linear models procedure of SAS was used to detect differences in observations between treatments by one-way analysis of variance. To eliminate discrepancies
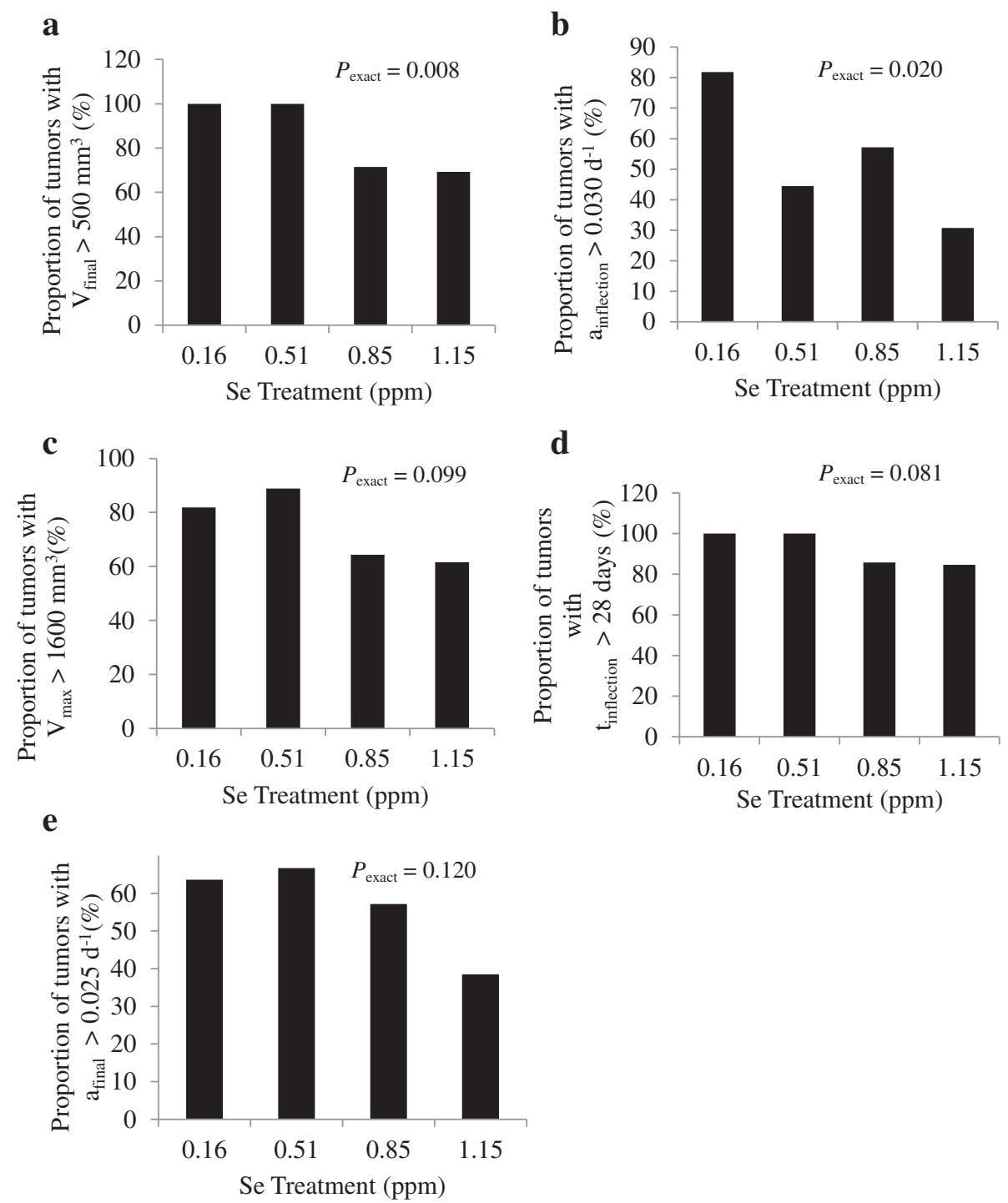

Figure 1 Proportion of large and fast-growing tumors within each treatment group. Proportion of tumors within each Se-casein treatment with a) final volume above $500 \mathrm{~mm}^{3}$, b) maximum growth rate above $0.03 \mathrm{~d}^{-1}$, c) maximum volume $\left(V_{\text {max }}\right)$ above $1600 \mathrm{~mm}^{3}$, d) inflection point after 28 days, and e) final growth rate above $0.025 \mathrm{~d}^{-1}$ were subjected to an exact Cochran-Armitage test for linear effect of dietary Se level. $P$-values are shown as $P_{\text {exact }}$ 
in initial growth rates, mice put on treatment three weeks or longer post-inoculation were excluded from the dataset. Tumors were also excluded based on a confidence grade, where a grade of 1 was assigned to regular-shaped tumors, and a grade of 0 to those with an irregular shape for which volume could not be accurately measured. Tumors with a grade of 0 were then excluded from analysis. Tumors were also excluded if their final volume was below $30 \mathrm{~mm}^{3}$, indicating inadequate estrogen implantation. Number of tumors excluded from $0.16,0.51,0.85$, and $1.15 \mathrm{ppm}$ treatments were $3,3,1$, and 1 , respectively. Orthogonal linear and quadratic contrasts of dietary Se level were determined with coefficients calculated in PROC IML of SAS to match the measured Se level. Because of a large variation around mean tumor growth characteristics within treatments, the proportion of tumors with growth characteristics above or below specified threshold values were calculated for each treatment (see Figure 1). Characteristics considered were final observed tumor volume $\left(\mathrm{V}_{\text {final }}\right), \mathrm{c}$, $V_{\text {max }}, t_{\text {inflection}}$, and $a_{\text {final }}$. The maximum specific growth rate (c) may also be described as the specific growth rate at the inflection point $\left(\mathrm{a}_{\text {inflection }}\right)$. Linear effects of dietary Se level on the proportions were detected using an exact Cochran-Armitage trend test in PROC FREQ of SAS. $P$-values less than 0.05 were reported as significant.

\section{Results}

Tumor growth dynamics

Growth of mammary tumor volumes during the 10 weeks of dietary treatment exhibited exponential growth to a plateau (Figure 2). There was a linear decrease in mean tumor volume at 70 days with increasing Se intake $(P=0.040$; Figure 3a) and a tendency for final tumor mass to decrease $(P=0.090$; Figure $3 b)$. Final tumor volume decreased $35 \%$ between 0.16 and $1.15 \mathrm{ppm}$ Se. Within each treatment, some tumors reached their maximum volume by 70 days, while others were still in a quasi-exponential growth phase at 70 days. In addition to variation in the time at which plateau was reached, there was a large variability in the plateau volume itself. Chignola et al. [13] speculated that this growth variability is an intrinsic property of each individual tumor. Even multicellular tumor spheroids grown under controlled culture conditions in vitro exhibit large growth variability [13]. In order to account for these variables, growth curves were fit with the Gompertz equation which generates estimates of the plateau volume $\left(\mathrm{V}_{\max }\right)$, and
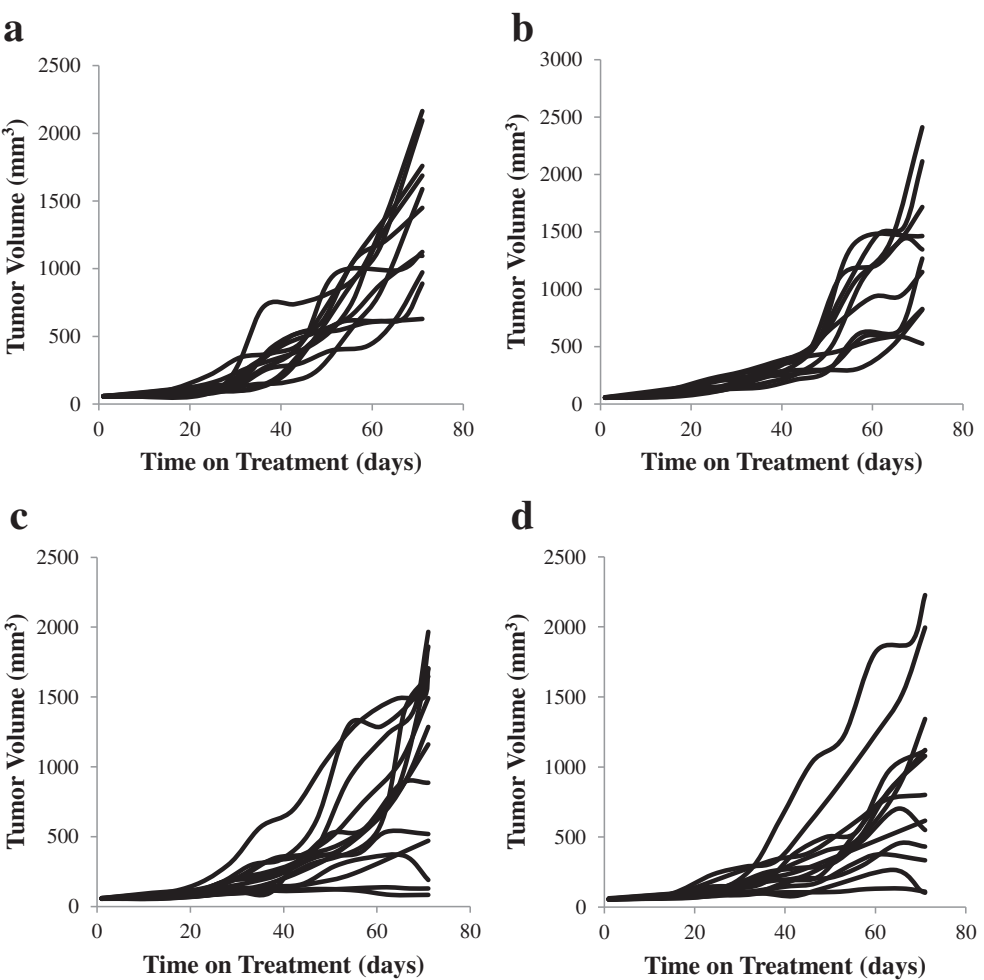

Figure 2 Tumor volume growth curves for individual mice in each treatment group. MCF-7 cells were xenografted into mammary fat pads of nude BALB/C mice implanted with slow-release estrogen pellets. Once tumor volumes reached $60 \mathrm{~mm}^{3}$ in volume, mice were assigned to dietary treatments of Se-casein at a) $0.16 \mathrm{ppm} \mathrm{Se}$, b) $0.51 \mathrm{ppm} \mathrm{Se}, \mathbf{c}) 0.85 \mathrm{ppm} \mathrm{Se}$, and d) $1.15 \mathrm{ppm}$ Se. Tumor volumes were estimated from caliper measurements once per week during treatment. 


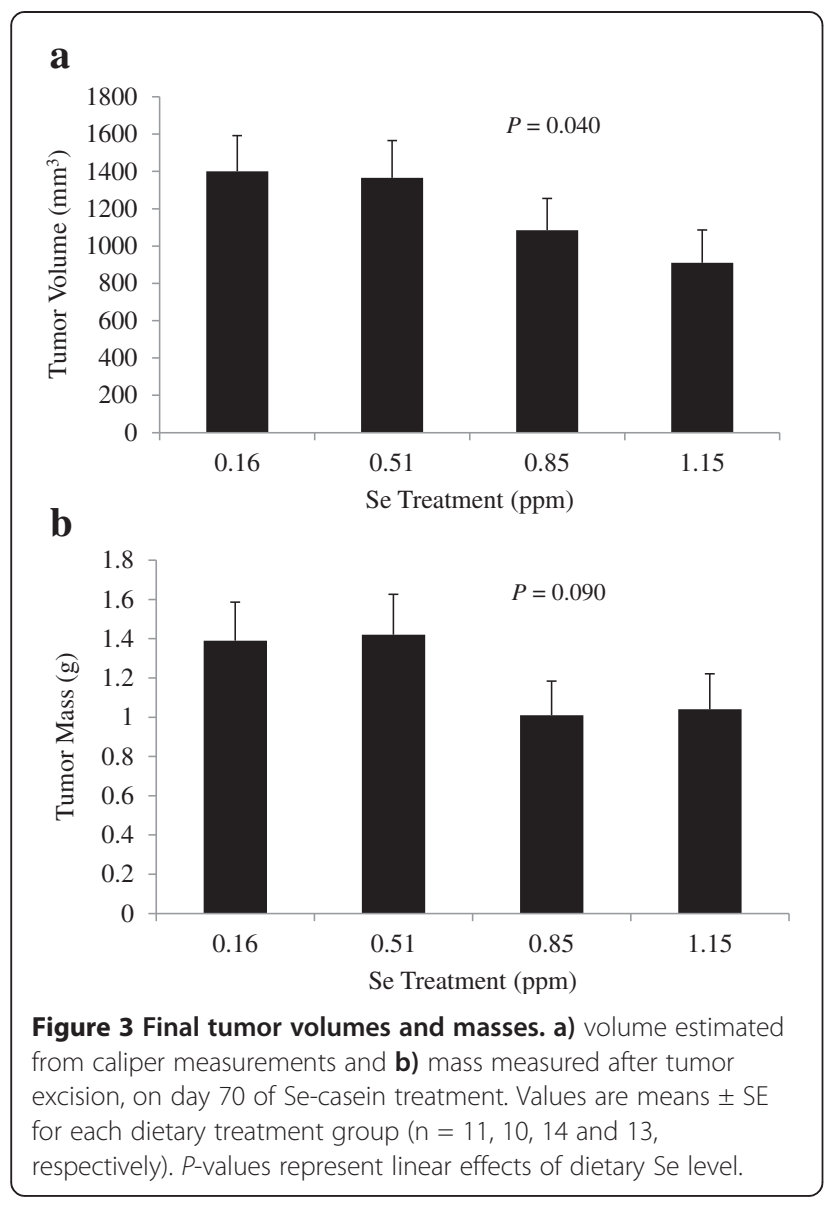

volumes (Equation 1) and specific growth rates (Equation 3) at any time point. Root MSPE averaged 16\% of mean tumor volume with no difference between treatments. One mouse on $0.51 \mathrm{ppm}$ Se was excluded from Gompertz analysis due to a physiologically implausible best-fit b-

Table 2 Gompertz fits to tumor growth curves and parameter estimates.

\begin{tabular}{lcccccc}
\hline \multicolumn{7}{c}{ Dietary Se level $(\boldsymbol{\mu g} / \mathbf{g}$ dry matter) } \\
\hline Measurement & 0.16 & 0.51 & 0.85 & 1.15 & SE & $P^{1}$ \\
$\mathrm{n}$ & 11 & 9 & 14 & 13 & & \\
$\mathrm{rMSPE}(\%$ of mean) & 14 & 16 & 17 & 16 & 3 & 0.458 \\
$\mathrm{~V}_{\max }\left(\mathrm{mm}^{3}\right)^{2}$ & 3451 & 5739 & 3486 & 2708 & 1162 & 0.348 \\
$\mathrm{~b}^{3}$ & 9.76 & 7.91 & 8.24 & 6.72 & 1.5 & 0.139 \\
$\mathrm{c}\left(\text { day }^{-1}\right)^{4}$ & 0.039 & 0.029 & 0.042 & 0.027 & 0.006 & 0.368 \\
$\mathrm{t}_{\text {inflection }}(\text { day })^{5}$ & 62 & 76 & 59 & 66 & 10 & 0.894 \\
$\mathrm{a}_{\text {final }}\left(\text { day }^{-1}\right)^{6}$ & 0.026 & 0.026 & 0.025 & 0.023 & 0.005 & 0.582 \\
\hline
\end{tabular}

${ }^{1}$ Linear effect of dietary Se level.

${ }^{2}$ Maximum volume.

${ }^{3}$ Gompertz growth parameter.

${ }^{4}$ Gompertz growth parameter describing maximum specific growth rate.

${ }^{5}$ Time of inflection point describing time at which maximum growth rate occurs.

${ }^{6}$ Final specific growth rate at day 70 of dietary treatment. value $>100,000$. There was no effect of Se-casein on mean $\mathrm{V}_{\text {max }}$ or other Gompertzian growth parameters of the mammary tumors (Table 2). Using the fitted Gompertz parameters, tumor volumes were predicted at weekly intervals and averaged by treatment to generate tumor growth curves for each Se inclusion level (Figure 4). Mean volumes at days 56, 63 and 70 on diet were significantly different between treatments, with decreasing volumes as Se-casein intake increased.

Effects of Se-casein on tumor growth were also evaluated by counting the number of large and fast-growing tumors on each treatment. The proportion of tumors with a final volume above $500 \mathrm{~mm}^{3}$ (Figure 1a) and the proportion of tumors with a maximum growth rate above $0.03 \mathrm{~d}^{-1}$ (Figure 1b) were both linearly decreased by Se inclusion level $\left(P_{\text {exact }}<0.02\right)$. Proportions of tu-

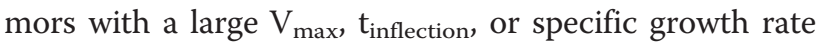
at 70 days were not affected by treatment (Figure 1c - e).

\section{Tissue analysis}

Average Se content of tumors increased linearly with Se intake from Se-casein $(P<0.001$; Figure 5$)$. The proportion of apoptotic cells in the 4 largest tumors on each treatment, which was assayed by DNA nick-end labeling (Figure 6a - d), also increased 2.4-fold with increasing Se levels $(P=0.007$; Figure 6e).

The expression of Bcl-2 protects cells against apoptosis, while Bax opposes the action of $\mathrm{Bcl}-2$ and aids in the induction of apoptosis. The ratio of Bax to $\mathrm{Bcl}-2$ is often considered a rheostat to control the level of apoptosis occurring in tissue. Western blot analysis of tumor tissue showed no significant treatment effects on the expression of $\mathrm{Bcl}-2$ or Bax proteins, or the ratio of Bax: Bcl-2 (Figure $7 \mathrm{a}-\mathrm{c}$ ).

The level of cyclin D1 expression was chosen as a marker of cell proliferation, as it is commonly overexpressed in breast cancer cells [14,15]. Western blot analysis of tumor tissue from each mouse subject did not reveal a significant difference in cyclin D1 expression between treatments (Figure 7d).

\section{Discussion}

Our findings show, for the first time, that dietary Se is effective at reducing growth of human mammary tumors in situ. The tumors originated from MCF-7 cells implanted in the mammary stroma of immune-compromised mice. The dietary Se was provided in casein isolated from the milk of cows fed Se-yeast in their diet. Increasing dietary Se from 0.16 to $1.15 \mathrm{ppm}$ caused a linear decrease in tumor volumes and the number of large tumors after 8 weeks (tumors with Vfinal $>500 \mathrm{~mm}^{3}$ ). The tumor volume effect was associated with a decrease in the number of tumors with a fast maximum growth rate. Although these observations indicate that growth rate was reduced, 


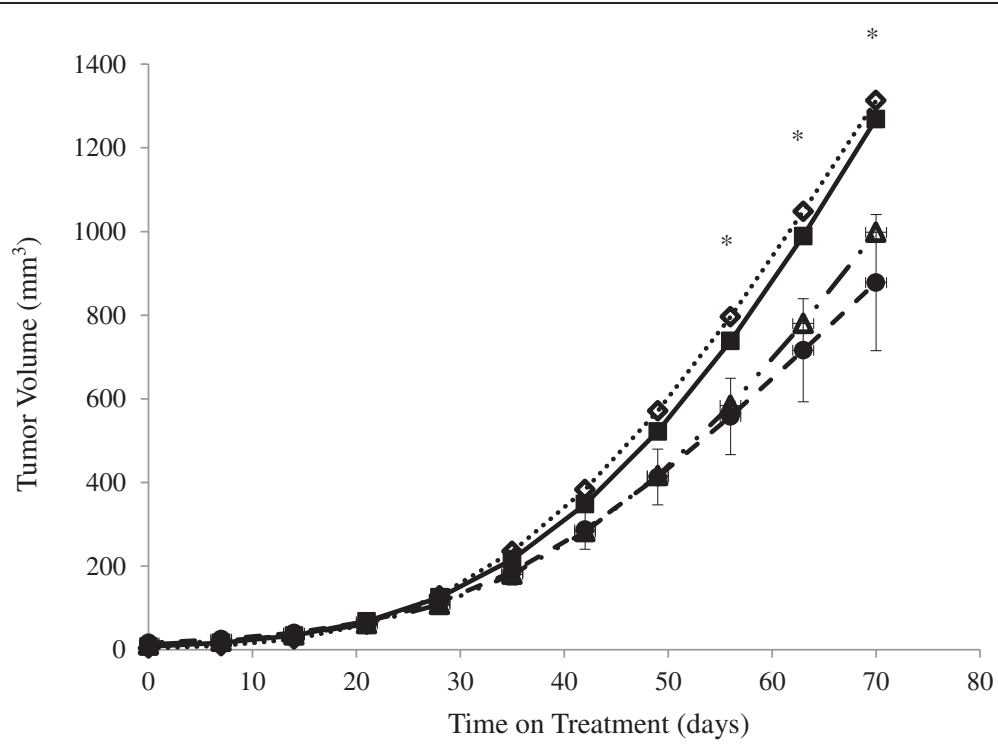

Figure 4 Mean tumor volumes predicted from fits of Gompertz equation to individual growth curves. Values are means for each Secasein treatment ( $n=11,9,14$ and 13, respectively). Error bars represent pooled SE of the mean. Asterisks indicate significant linear effects of dietary Se from Se-casein $(P<0.05)$. 0.16 ppm Se $(n=11), 0.51$ ppm Se $(n=9), 0.85$ ppm Se $(n=14), 1.15$ ppm Se $(n=13)$.

the maximum volume that tumors were predicted to reach $\left(\mathrm{V}_{\max }\right)$, and the number of tumors with a large $\mathrm{V}_{\max }$, were not affected by Se-casein. Maximum volume and growth rate were generated using Gompertz fits of the observed growth data. Growth rate of tumors is related to the net difference between proliferation and death of individual cells, while final volume is related to the ability to maintain oxygen and nutrient supply to the tumor, particularly its inner core [16]. Thus, Se-casein appears to affect cancer cell turnover but not supply or extraction of nutrients by the tumor.

Our results add a new dimension to the findings that dietary Se prevents oncogenesis in chemical-induction models of mammary and colorectal cancer $[6,12]$, and to

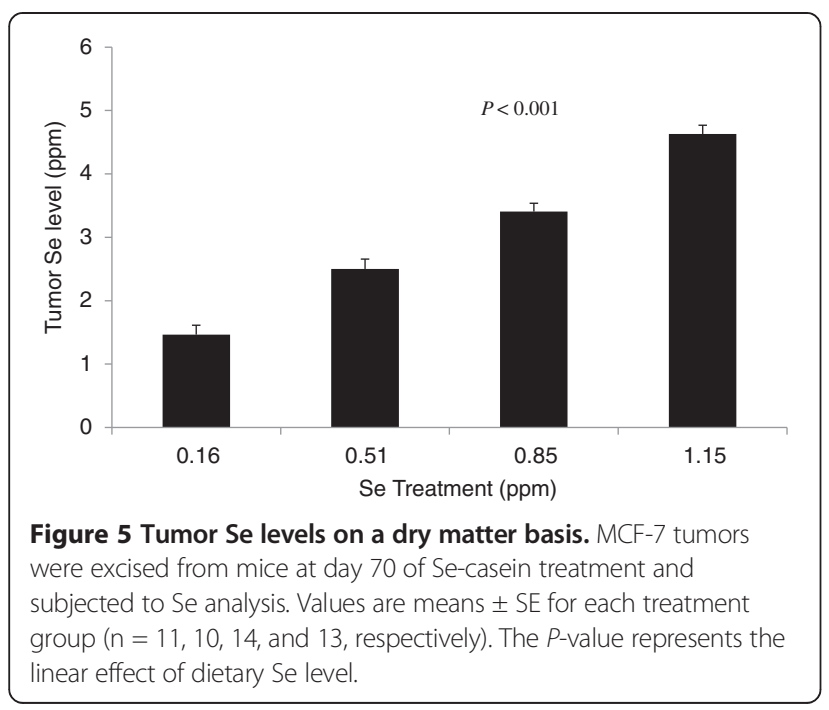

the growing body of evidence that Se compounds are effective against established tumors [17]. Selenium is thought to affect tumor growth by inducing cell cycle arrest and apoptosis [18-20]. Generally speaking, inorganic selenium is reduced to hydrogen selenide which results in reactive oxygen species-mediated induction of singlestrand DNA breaks and apoptosis in various cancer cell lines, including leukemia, mammary and prostate cancers [21-23]. Organic selenium sources, on the other hand, are able to induce apoptosis without the genotoxic effects, ostensibly via the metabolite methylselenol [6]. Putative mechanisms by which methylselenol prevents cancer include caspase activation and dephosphorylation of prosurvival Akt and extracellular signal-related kinase 1/2 [24].

Casein isolated from the milk of cows fed Se-yeast contains organic Se, primarily in the forms of selenomethionine and selenocysteine [11]. These organic forms of Se are readily concentrated in tissues because of sequestration in proteins. In the current study, tumors from mice fed 1.15 ppm Se-casein accumulated an average Se concentration of $4.58 \mathrm{ppm}$, whereas s.c. injection of $1.5 \mathrm{ppm}$ inorganic Se as selenite in a previous study resulted in MCF-7 tumor Se concentrations of $1.55 \mathrm{ppm}$ [25]. Whether the higher tumor Se concentration due to Se-casein consumption translates into greater exposure to hydrogen selenide or methylselenol remains unknown. However, we observed a significantly higher number of apoptotic cells in high-Se tumors as compared to low-Se tumors. In vitro, the $\mathrm{IC}_{50}$ of SeMet against MCF-7 cells was $45 \mu \mathrm{M}$ [26]. Assuming it is all SeMet, the $4.58 \mathrm{ppm}$ Se we found in mammary tumors is equivalent to a concentration of $23 \mu \mathrm{M}$ SeMet. The $35 \%$ decrease in final tumor volume we observed on 


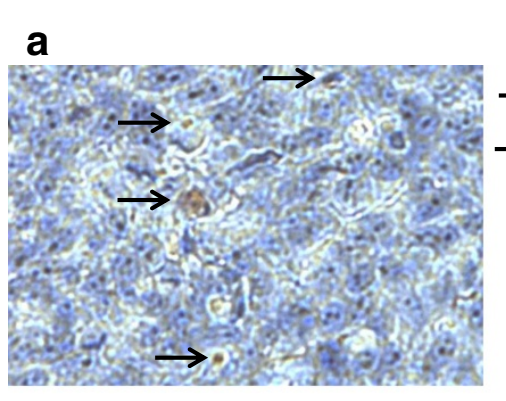

C

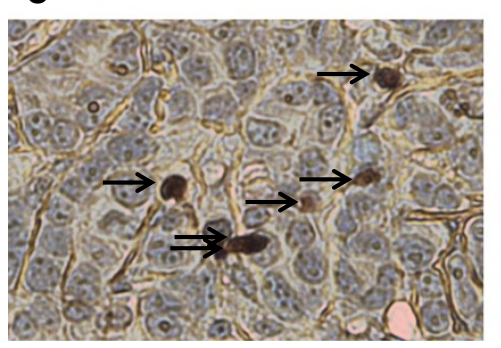

\section{b}

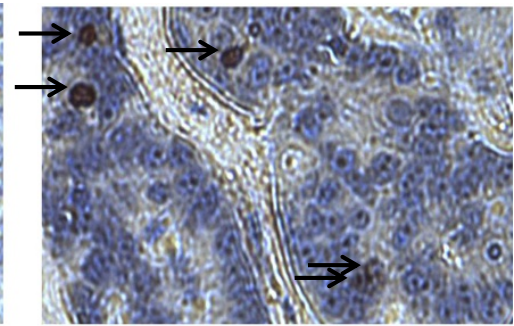

d

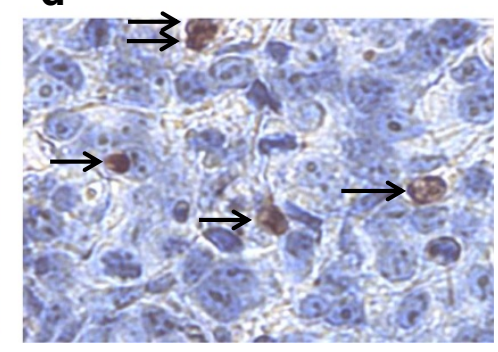

e

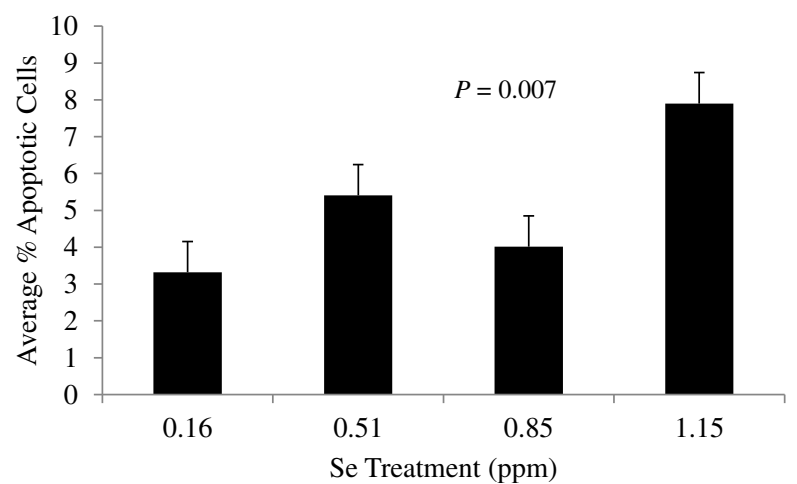

Figure 6 Effect of Se-casein on apoptotic cell number. After $70 \mathrm{~d}$ on Se-casein treatment, the 4 largest MCF-7 tumors on each treatment were excised, embedded in wax, and sectioned at $5 \mu \mathrm{m}$ onto microscope slides. The TUNEL assay was used to identify apoptotic cells and nuclei were counterstained with hematoxylin. a) mouse 13, $0.16 \mathrm{ppm} \mathrm{Se.} \mathrm{b)} \mathrm{mouse} \mathrm{26,} 0.51 \mathrm{ppm} \mathrm{Se.} \mathrm{c)} \mathrm{mouse} \mathrm{3,} 0.85$ ppm Se. d) mouse $15.1 .15 \mathrm{ppm}$ Se. Arrows indicate apoptotic cells. e) Apoptotic cell number was expressed as a percentage of total nuclei, counting 1500-2000 nuclei per sample. Values are means \pm SE for each treatment group. The $P$-value represents the linear effect of dietary Se level.

the high-Se diet is consistent with tumor Se concentrations slightly less than the $\mathrm{IC}_{50}$. The pro-apoptotic effect of Se on cancer cells in vitro and in vivo is well documented $[5,6,17]$ but effects of dietary Se on apoptosis in human mammary tumors have not previously been reported.

Redman and coworkers [26] investigated the effects of SeMet on four cell lines in vitro: MCF-7 breast carcinoma, UACC-375 melanoma, DU-145 prostate cancer, as well as normal diploid fibroblasts. This study investigated the $\mathrm{IC}_{50}$ of SeMet for for each cell line. SeMet concentrations ranged from 100-10000 $\mu \mathrm{M}$. SeMet inhibited growth in all cell lines in a dose-dependent manner. In MCF-7 cells, cell viability was not affected by $0.01-10 \mu \mathrm{M}$, while $100-1000 \mu \mathrm{M}$ significantly inhibited cell growth. In UACC-375 melanoma cells, concentrations greater than $1 \mu \mathrm{M}$ were required to significantly inhibit cell growth. In prostate cancer cells DU-145, concentrations beyond $10 \mu \mathrm{M}$ showed a marked decline in cell growth. In contrast to the micromolar concentrations of SeMet shown to inhibit cancer cell lines, inhibition of growth in diploid fibroblasts required millimolar concentrations. These results indicated that DU145 prostate cancer cells are the most sensitive to SeMet treatment with a $\mathrm{IC}_{50}$ of $40 \mu \mathrm{M}$, followed by MCF-7 and UACC-375 with $45 \mu \mathrm{M}$ and $50 \mu \mathrm{M}$, respectively. Fibroblasts required $1 \mathrm{mM}$ SeMet to induce $50 \%$ inhibition. According to these results, cancer cells may be more sensitive to selenium treatment than normal cells [26]. It was postulated that these discrepancies may be due to differences in uptake and metabolism of SeMet to anticarcinogenic metabolites, as SeMet may be metabolized to methylselenol or SeCys, which in turn is hydrolyzed to hydrogen selenide [26]. 

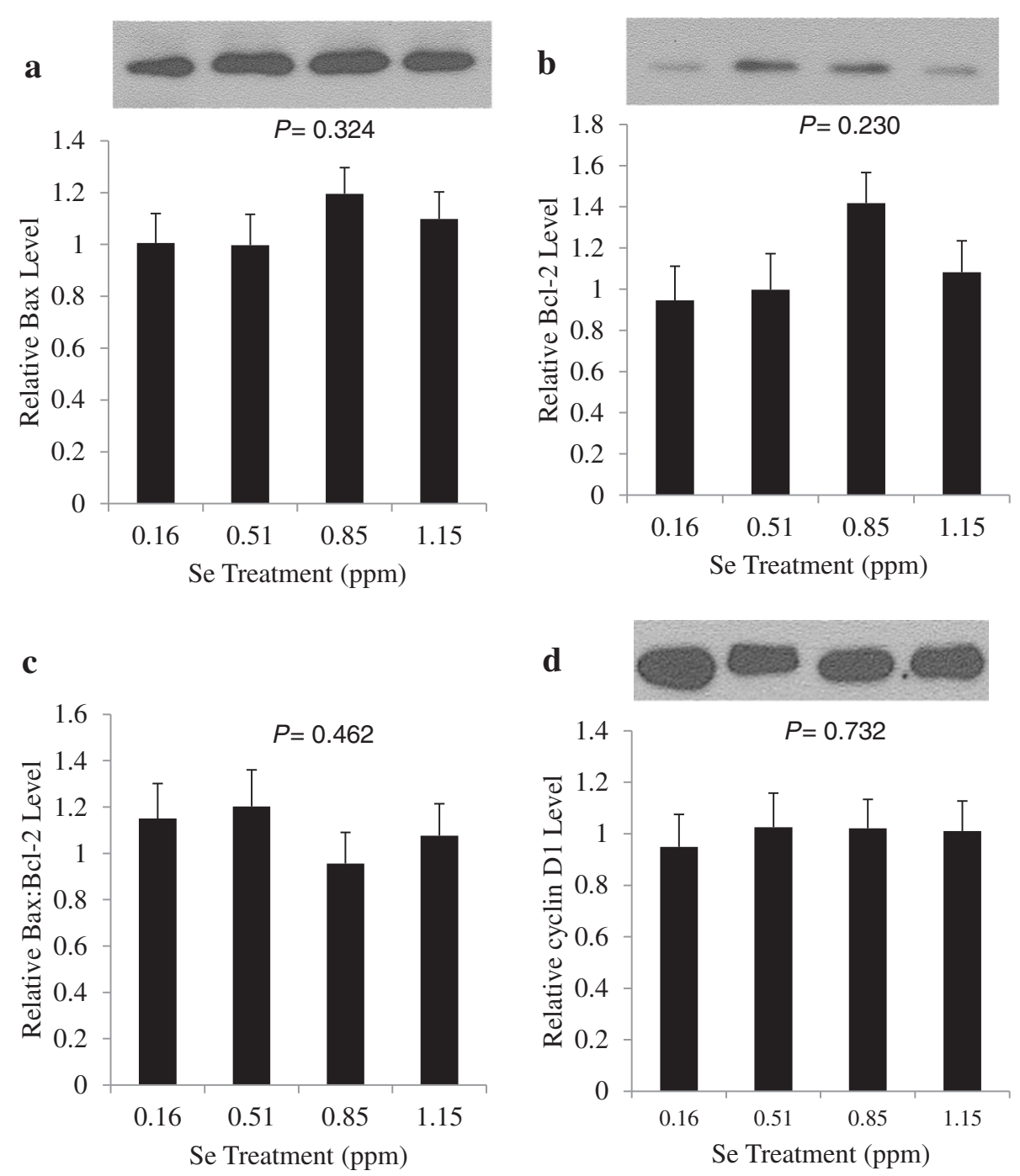

Figure 7 Effects of selenium treatments on Bax, Bcl-2 and cyclin D1 protein levels. After $70 \mathrm{~d}$ of Se-casein treatment, tumors were excised from mice and subjected to western blot analysis for a) Bax, b) Bcl-2, c) Bax:Bcl-2 ratio and d) cyclin D1. Expression levels were normalized to $\beta$-tubulin. Values in bar graphs are means \pm SE for each treatment group $(n=11,10,14$ and 13 , respectively). P-values represent linear effects of dietary Se level.

Similar to Kaeck et al. [27], we found no effect of Se on Bax or Bcl-2 expression in tumors, despite an increase in apoptosis. In contrast, MSeA increased Bax and decreased Bcl-2 expression in three lines of prostate cancer cells [28]. While Bcl-2 and Bax are considered the main players in controlling programmed cell death, apoptosis is an intricate process with several points of control that have been shown to be affected by Se, including expression of Bcl-x1, Bak and Bid [28,29]. The results herein indicate that Se-casein was able to induce apoptosis in MCF-7 cells independently of the Bax:Bcl-2 rheostat, suggesting an alternative apoptotic pathway is being targeted.

In addition to apoptosis, tumor growth is determined by cell proliferation. Se is known to downregulate several genes controlling the expression of cell cycle proteins, including cyclins A and cyclin D1 [20]. Cyclin D1 is an important regulator in the early stages of the cell cycle, controlling the transition from the first gap phase to the synthesis phase. We chose cyclin D1 as a marker of tumor proliferation. While this protein is overexpressed in over half of breast cancer cases,cyclin D1 levels in MCF-7 cells are similar to those found in normal mammary epithelial cells $[14,15,30]$, yet cyclin D1 has been shown to play an essential role in cell cycle progression in MCF-7 cells [31]. We observed no effect of Se-casein treatment on cyclin D1 expression. In vitro study shows that $5 \mu \mathrm{M}$ MSeA downregulates cyclin D1 in premalignant human breast cells at an early time-point and upregulates cyclin D1 at a later time point [32]. Thus, 
interruption of cyclin D1-mediated cell cycle progression does not appear to be responsible for the inhibitory effects of Se-casein on tumor growth observed in the current study. Selenium, however, has been shown to downregulate several genes controlling the expression of cell cycle proteins, including cyclin A, CDC25A, CDK4, PCNA and E2F [33].

Many different forms of dietary Se have been tested for efficacy against the development and progression of cancer including SeMet, MSeA, SeMSC (Se-methylselenocysteine), and Se-enriched broccoli, garlic and milk protein $[6,12,27,34,35]$. The highest dose of Se we administered via dietary casein was $1.15 \mathrm{ppm}$, which was insufficient to cause more than a $35 \%$ decrease in tumor growth. However, the linearity of the response to dose suggests that higher doses could have a greater inhibitory effect. Organic Se doses up to $5 \mathrm{ppm}$ Se have been fed to animals in studies of cancer chemoprevention. Another option might be to use Se-casein in conjunction with other chemotherapeutics. Se appears to sensitize cancer cells to apoptosis while reducing the toxic effects of therapy and selectively protecting normal cells [36]. For instance, Li et al. [37] showed that Se in the form of MSeA sensitized MCF-7 cells to doxorubicin-induced apoptosis [37]. Another study found that MSeA acted synergistically with paclitaxel in the treatment of triplenegative breast cancer to increase induction of caspasemediated apoptosis, cell cycle arrest, and inhibition of cell proliferation [38].

We have shown that 1.15 ppm dietary Se from selenized casein can effectively reduce tumor progression in an MCF-7 xenograft breast cancer model. Results of a DNA nick-end labeling assay support the claim that Se-casein reduces breast cancer cell growth by increasing the number of cells undergoing apoptosis.

The literature indicates that the optimal Se intake is $250-300$ ug per day, however the interaction of Se with other elements must be considered [39]. These elements include, but are not limited to, $\mathrm{As}, \mathrm{Cu}, \mathrm{Ni}, \mathrm{Co}, \mathrm{Cr}, \mathrm{Mn}$, $\mathrm{Zn}, \mathrm{Cd}, \mathrm{Sn}, \mathrm{Pb}, \mathrm{Hg}, \mathrm{Bi}, \mathrm{Mo}, \mathrm{Ag}$, and $\mathrm{Au}$, Evidence from animal experiments suggest that chronic exposure to these elements counteracts the anticarcinogenic effects of Se [39]. This indicates that the presence of these elements in the diet must be well characterized before a claim can be made regarding Se-casein as a cancerprotective supplement.

While the average Se intake in most countries is sufficient to prevent Se deficiencies, it may be suboptimal for protection against a number of adverse health conditions. This is because the amount of selenium in the human diet is largely dependent on the soil content where crops destined for human consumption are cultivated. Therefore, providing Se-enriched casein through milk has the potential to not only prevent deficiency, but also provide the supranutritional levels required to prevent a disease like cancer. This study showed the potential for Se-casein to be an effective treatment of breast cancer, suggesting its potential role in adjuvant therapy. Further study is required to elucidate the precise mechanism through which supranutritional Se-casein levels reduce carcinogenesis. The effects of high-Se casein on normal cells in addition to cancerous cells should also be wellcharacterized before it may be approved as an effective dietary supplement for chemoprevention in order to eliminate safety concerns.

\section{Conclusions}

Increasing dietary Se from 0.16 to 1.15 ppm caused a linear decrease in tumor volumes and the number of large tumors after 8 weeks. The tumor volume effect was associated with a decrease in the number of tumors with a fast maximum growth rate, however the maximum volume that tumors were predicted to reach and the number of tumors with a large maximum volume were not affected by Se-casein. Taken together, this suggests that dairy Se affects the turnover of cells in the tumor, but not its nutrient supply. We have shown that $1.1 \mathrm{ppm}$ dietary Se from selenized casein can effectively reduce tumor progression in an MCF-7 xenograft breast cancer model. These results show promise for selenized milk protein as an effective supplement during the course chemotherapy.

\section{Abbreviations \\ Akt/PKB: Protein Kinase B; Bak: Bcl-2 homologous antagonist killer; Bax: Bcl-2 associated X protein; Bcl-2: B-cell lymphoma 2; DAB: Diaminbenzidine; $\mathrm{IC}_{50}$ : Half maximal inhibitory concentration; MSeA: Methylseleninic acid; SeMet: Selenomethionine; TUNEL: Terminal deoxynucleotidyltransferasedUTPnick end labeling.}

Competing interests

The authors declare that they have no competing interests.

\section{Authors' contributions}

JW cultured cells, formulated diets, conducted the animal trial, collected and analyzed samples, ran statistical analyses, and drafted the manuscript. JK participated in tissue analysis and preparation for publication of the manuscript. PS and SC participated in milk processing and diet formulation. BC participated in the conception, design, and drafting of the manuscript. RM participated in design and drafting of the manuscript. MC participated in conception and design of the manuscript. JC participated in conception, design, statistical evaluation and interpretation of the results, and provided significant input into drafting of the manuscript. All authors have read and approved the manuscript for publication.

\section{Acknowledgements}

We thank the staff at Elora Dairy Research Centre who contributed to cow feeding and milk acquisition and the Guelph Food and Technology Centre staff at the University of Guelph participated who assisted with milk processing. We thank the Central Animal Facility staff for their excellent animal care and, in particular, Jackie Rombeek who participated in animal care and surgery and Marcus Litman for acting as our veterinary consultant. Financial support was provided by Dairy Farmers of Ontario, Alltech Canada, Inc., and NSERC Canada. 


\section{Author details}

${ }^{1}$ Centre for Nutrition Modelling, Department of Animal and Poultry Science, University of Guelph, Guelph, ON N1G 2W1, Canada. 'Department of Biomedical Sciences, University of Guelph, Guelph, ON N1G 2W1, Canada. ${ }^{3}$ Department of Food Science, University of Guelph, Guelph, ON N1G 2W1, Canada.

Received: 23 April 2013 Accepted: 8 October 2013

Published: 23 October 2013

\section{References}

1. Wycherly BJ, Moak MA, Christensen MJ: High dietary intake of sodium selenite induces oxidative DNA damage in rat liver. Nutr Cancer 2004, 48:78-83.

2. Yoshizawa K, Willet WC, Morris SJ, Stampfer MJ, Spiegelman D, Rimm EB, Giovannucci E: Study of prediagnostic selenium level in toenails and the risk of advanced prostate cancer. J Natl Cancer Inst 1998, 90:1219-1224.

3. Clark LC, Combs GF, Turnbull BW, Slate EH, Chalker DK, Chow J, Davis LS, Glover RA, Graham GF, Gross EG, Krongrad A, Lesher JL, Park HK, Sanders BB, Smith CL, Taylor JR: Effect of selenium supplementation for cancer prevention in patients with carcinoma of the skin. J Am Med Assoc 1996, 276:1957-1963.

4. Jiang C, Wang Z, Ganther H, Lu J: Distinct effects of methylseleninic acid versus selenite on apoptosis, cell cycle, and protein kinase pathways inDU145 human prostate cancer cells. Mol Cancer Ther 2002, 1:1059-1066.

5. Kim $T$, Jung $U$, Cho $D$, Chung A: Se-Methylselenocysteine induces apoptosis through caspase activation in HL-60 cells. Carcinogenesis 2001 22(4):559-565.

6. Ip C, Thompson HJ, Zhu Z, Ganther HE: In vitro and in vivo studies of methylseleninic acid: evidence that a monomethylated selenium metabolite is critical for cancer chemoprevention. Cancer Res 2000, 60:2882-2886

7. Sinha R, Medina D: Inhibition of cdk2 kinase activity by Semethylselenocysteine in synchronized mouse mammary epithelial cells. Carcinogenesis 1997, 18:1541-1547.

8. Sinha R, Unni E, Ganther HE, Medina D: Methylseleninic acid, a potent growth inhibitor of synchronized mouse mammary epithelial tumor cells in vitro. BiochemPharmacol 2000, 61:311-317.

9. Rayman MP: Selenium in cancer prevention: a review of the evidence and mechanism of action. Proc Nutr Soc 2005, 64:527-542

10. Combs GF: Should intakes with beneficial actions, often requiring supplementation, be considered for RDAs? J Nutr 1996, 126:2373-2376.

11. Phipps RH, Grandison AS, Jones AK, Juniper DT, Ramos-Morales E, Bertin G: Selenium supplementation of lactating dairy cows: effects on milk production and total selenium content and speciation in blood, milk and cheese. Animal 2008, 2(11):1610-1618.

12. Hu Y, Mclntosh GH, Le Leu RK, Woodman R, Young GP: Suppression of colorectal oncogenesis by selenium-enriched milk proteins: apoptosis and K-ras mutations. Cancer Res 2008, 68:4936-4944.

13. Chignola R, Schenetti A, Andrighetto G, Chiesa E, Foroni R, Sartoris S, Tridente G, Liberati D: Forecasting the growth of multicell tumour spheroids: implication for the dynamic growth of solid tumours. Cell Prolif 2000, 33:219-229.

14. Buckley MF, Sweeney KJ, Hamilton JA, Sini RL, Manning DL, Nicolson Rl, Defazio A, Watts CK, Musgrove EA, Sutherland RL: Expression and amplification of cyclin genes in human breast cancer. Oncogene 1993, 8:2127-2133.

15. van Diest PJ, Michalides RJAM, Jannink I, van der Valk P, Peterse HL, de Jong JS, Meijer CJLM, Baak JPA: Cyclin D1 expression in invasive breast cancer: correlations and prognostic value. Am J Pathol 1997, 150:705-711.

16. Kiran KL, Jayachandran D, Lakshminarayanan S: Mathematical modelling of avascular tumour growth based on diffusion of nutrients and its validation. CanSocChemEng 2009, 87:732-740

17. Li Z, Latonya C, Belame A, Thiyagarajah A, Salvo AA, Burow ME, Rowan BG: Combination of methylselenocysteine with tamoxifen inhibits MCF-7 breast cancer xenografts in nude mice through elevated apoptosis and reduced angiogenesis. Breast Cancer Res Treat 2009, 118:33-43.

18. Whanger PD: Selenium and its relationship to cancer: an update. Br J Nutr 2004, 91:11-28.

19. Ip C: Lessons from basic research in selenium and cancer prevention J Nutr 1998, 128:1845-1854.
20. El-Bayoumy K, Sinha R: Molecular chemoprevention by selenium: A genomic approach. Mutation Res 2005, 591:224-236.

21. Lu J, Kaeck M, Jiang C, Wilson AC, Thompson HJ: Selenite induction of DNA strand breaks and apoptosis in mouse leukemic L1210 cells. BiochemPharmacol 1994, 47:1531-1535.

22. Thompson HJ, Wilson A, Lu JX, Singh M, Jiang C, Upadhyaya P, El- Bayoumy $\mathrm{K}, \mathrm{IpC}$ : Comparison of the effects of an organic and an inorganic form of selenium on a mammary carcinoma cell line. Carcinogenesis 1994, 15:183-186.

23. Jiang C, Wang Z, Ganther H, Lu J: Caspases as key executors of methyl selenium-induced apoptosis (anoikis) ofDU-145 prostate cancer cells. Cancer Res 2001, 61:3062-3070.

24. Wang Z, Jiang C, Lu J: Induction of caspase-mediated apoptosis and cellcycle G1 arrest by selenium metabolite methylselenol. Mol Carcinog 2002, 34:113-120.

25. Watrach AM, Milner JA, Watrach MA, Poirier KA: Inhibition of human breast cancer cells by selenium. Cancer Lett 1984, 25:41-47.

26. Redman C, Scott JA, Baines AT, Basye JL, Clark LC, Calley C, Roe D, Payne CM, Nelson MA: Inhibitory effect of selenomethionine on the growth of three selected human tumor cells lines. Cancer Lett 1998, 125:103-110.

27. Kaeck M, Lu J, Strange R: Differential induction of growth arrest inducible genes by selenium compounds. Biochem Pharmacol 1997, 53:921-926.

28. Reagan-Shaw S, Nihal M, Ahsan H, Mukhtar H, Ahmad N: Combination of vitamin $\mathrm{E}$ and selenium causes an induction of apoptosis of human prostate cancer cells by enhancing Bax/Bcl-2 ratio. Prostate 2008, 68:1624-1634.

29. Chen T, Wong Y: Selenocystine induces caspase-independent apoptosis in MCF-7 human breast carcinoma cells with involvement of p53 phosphorylation and reactive oxygen species generation. Int J Biochem Cell Biol 2009, 41:666-676.

30. Zwijsen RML, Klompmaker R, Weintjens EBHGM, Kristel PMP, van der Burg B, Michalides RJAM: Cyclin D1 triggers autonomous growth of breast cancer cells by governing cell cycle exit. Mol Cell Biol 1996, 16:2554-2560.

31. Bartkova J, Lukas J, Müller H, Lutzhoft D, Strauss M, Bartek J: Cyclin D1 protein expression and function in human breast cancer. Int J Cancer 1994, 57:353-361.

32. Dong Y, Ganther HE, Stewart C, Ip C: Identification of molecular targets associated with selenium-induced growth inhibition in human breast cells using cDNA microarrays. Cancer Res 2002, 62:708-714.

33. El-Bayoumy K, Sinha R: Molecular chemoprevention by selenium: A genomic approach. Mutat Res 2005, 591:224-236.

34. Finley JW, Davis CD, Feng Y: Selenium from high selenium broccoli protects rats from colon cancer. J Nutr 2000, 130:2384-2389.

35. Ip C, Lisk DJ, Thompson HJ: Selenium-enriched garlic inhibits the early stage but not the late stage of mammary carcinogenesis. Carcinogenesis 1996, 17:1979-1982

36. Cao S, Durrani FA, Rustum YM: Selective modulation of the therapeutic efficacy of anticancer drugs by selenium containing compounds against human tumor xenografts. Clin Cancer Res 2004, 10:2561-2569.

37. Li S, Zhou Y, Wang R, Zhang H, Dong Y, Ip C: Selenium sensitizes MCF-7 breast cancer cells to doxorubicin-induced apoptosis through modulation of phospho-Akt and its downstream substrates. Mol Cancer Ther 2007, 6:1031-1038.

38. Qi Y, Fu X, Xiong Z, Zhang H, Hill SM, Rowan BG, Dong Y: Methylseleninic acid enhances paclitaxel efficacy for the treatment of triple-negative breast cancer. PLOS ONE 2001, 7(2):e31539. doi:10.1371/journal. pone.0031539.

39. Schrauzer GN: Selenium and selenium-antagonistic elements in nutritional cancer prevention. Crit Rev Biotechnol 2009, 29(1):10-17.

doi:10.1186/1471-2407-13-492

Cite this article as: Warrington et al: Selenized milk casein in the diet of $\mathrm{BALB} / \mathrm{C}$ nude mice reduces growth of intramammary MCF-7 tumors. BMC Cancer 2013 13:492 